\title{
PRELIMINARY ANALYSIS OF WATER PRODUCTION RATE AND TURBIDITY IN SOURCE WATER FROM MOUNT MERAPI USING A MULTI-LAYER SAND FILTER
}

\author{
Setya Winarno ${ }^{1}$ \\ ${ }^{l}$ Civil Engineering Department, Universitas Islam Indonesia, Indonesia
}

\begin{abstract}
In Indonesia, little importance is placed on the coverage of water supply services and even less importance is focused on water filtration. Today, many people in the surroundings of Merapi Mountain, Yogyakarta City, Indonesia are utilizing one-layer sand filtration, which is frequently used as a robust method of removing suspended solids from water. Because they have a single layer of sand filtration medium with a diameter of about 0.5-3 mm, sand filters remove only relatively large solids. This paper elaborates the effective size of each sand granule with two sand layers in terms of the water production rate and turbidity in order to benefit people in the surroundings of Mount Merapi. A flow rate study was conducted by creating three parallel sand boxes (length $=20 \mathrm{~cm}$, width $=30 \mathrm{~cm}$, and height $=80 \mathrm{~cm})$. Each box consisted of two sand layers with a height of $20 \mathrm{~cm}$ each. Box 1 was filled with $20 \mathrm{~cm}$ of $0.5-\mathrm{mm}$ sand at the top and $20 \mathrm{~cm}$ of $0.3-\mathrm{mm}$ sand at the bottom. Box 2 had $20 \mathrm{~cm}$ of $1.0-\mathrm{mm}$ sand at the top and $20 \mathrm{~cm}$ of 0.5-mm sand at the bottom, while Box 3 had $20 \mathrm{~cm}$ of $1.5-\mathrm{mm}$ sand at the top and $20 \mathrm{~cm}$ of $1.0-\mathrm{mm}$ sand at the bottom. The three sand boxes were then compared. From the obtained results, the relationship between average flow rate and turbidity was found and had a positive linear trend of 4.881 NTU/Lh ${ }^{-1}$. To fulfil the Decree of the Indonesian Health Minister No. 907/MENKES/SK/VII/2002, which specifies that the maximum turbidity for clean water is 5 NTU, Box 2 is an effective solution with a flow rate of up to $2.9 \mathrm{Lh}^{-1}$. However, long-term investigations should be conducted to assess how these relationships change over the expected lifetime of the sand filter.
\end{abstract}

Keywords: Sourcewater, Production Rate, Turbidity, Sand Filter

\section{INTRODUCTION}

In Indonesia, there are many active mountains that have erupted recently. In every eruption, they emit abundant volcanic sand. Communities in the surrounding area utilize the sand for a variety of household activities. Although in many regions in Indonesia little importance is given to the use of volcanic sand for slow water filtration, some people in the surroundings of Mount Merapi, Yogyakarta City, Indonesia employ the sand to purify source water for daily life. As it uses primarily local materials and labour, this represents a sustainable water treatment technology for poor communities. The use of slow sand filtration to treat source water has been known for a long time. A similar situation is also found in Algeria [1] and Kupang, Indonesia [8].

In general, sand filtration is primarily used for reducing turbidity as a result of suspended matter as well as floating and sinkable particles. The source water flows vertically through a bed of sand. The longer the duration of filtration is the more abundant the dirt or polluted particles in the filtration unit. Particles and impurities are removed by two mechanisms: mechanical removal and removal by adsorption. Mechanically, large particles become lodged and cannot continue downward through the filtration medium. In the filter bed, large particles jointly form a macro-porous lump. Through absorption, deep dirt involves smaller particles that are bound to the sand particles. Particles stick to the medium and cannot continue downward through it. If the flow rate of filtration is low, the sand must be rinsed.

Sectors where sand filtration is implemented include clean water production, swimming pools, groundwater treatment, and the fruit- and vegetable-processing, food, and drinkingwater industries. Currently, Merapi people utilize one-layer sand filtration, which is frequently used as a robust method to remove suspended solids from water. Because they have a homogeneous filtration medium comprising one layer of sand with a diameter of about $0.5-3 \mathrm{~mm}$, sand filters remove only relatively large solids.

A long-term investigation described by Salvinelli and Elmore [6] showed that flow rates decrease over time and that turbidity negatively affects both the average flow rate and the rate at which it decreases. Mihelcic et al. [5] stated that turbidity has a negative impact on many water treatment processes in different ways, including clogging filters and therefore reducing their effectiveness. Van Halem et al. [9] concluded that a potential cause of failure is the physical fouling by colloids and that neither organic nor inorganic fouling are the principal causes of clogging. Therefore cleaning the filtering unit provides a temporary benefit but 
does not prevent long-term clogging, and thus the flow rate is the limiting factor of the sand filtration lifetime and sustainability. According to Salvinelli and Elmore [6], turbidity seems to be the principal indicator in characterizing the sand filtration lifetime in terms of the water production capacity. In addition, the relationship between the sand filtration flow rate and turbidity is not well understood. Indeed, the flow rate is a powerful indicator of the sand filtration performance, but it is unclear how it can be representative of the average flow rate. Moreover, the choices of economical and effective processes are the major concern of this approach.

Therefore, this paper elaborates the effective size of each granule of sand with two layers of sand in terms of the water production rate and turbidity for source water from Mount Merapi under controlled conditions using three sand filters of different sizes. The primary purpose of this study is to assess the relation between sand size, turbidity, and flow rate. This study in particular aims to identify the effective size of sand as a water filter in order to support the Decree of the Indonesian Health Minister No. 907/MENKES/SK/VII/2002 [3], which specifies that the maximum turbidity for clean water is 5 NTU (Nephelometric Turbidity Units).

\section{METHODS}

This research was conducted in the Innovation Center of Universitas Islam Indonesia to assess how the turbidity impacts the sand filtration flow rate in three types of filtering units. It was conducted by creating three parallel sand boxes, $20 \mathrm{~cm}$ in length, $30 \mathrm{~cm}$ in width, and $80 \mathrm{~cm}$ in height. Each box consisted of two sand layers with a height of $20 \mathrm{~cm}$ each. Box 1 was filled with fine sand $(20 \mathrm{~cm}$ of $0.5-\mathrm{mm}$ sand at the top and $20 \mathrm{~cm}$ of $0.3-\mathrm{mm}$ sand at the bottom). Box 2 was filled with medium-size sand $(20 \mathrm{~cm}$ of $1.0-\mathrm{mm}$ sand at the top and $20 \mathrm{~cm}$ of $0.5-\mathrm{mm}$ sand at the bottom), and Box 3 was filled with coarse sand $(20 \mathrm{~cm}$ of $1.5-\mathrm{mm}$ sand at the top and $20 \mathrm{~cm}$ of $1.0-\mathrm{mm}$ sand at the bottom). The three sand columns were then compared in terms of flow rate and turbidity after filtration.

First, a 24 h constant head flow rate test was conducted in order to establish a baseline daily average flow rate for each individual filter, called the initial flow rate. A constant head flow rate test of all the filters used in the study was conducted in order to establish a baseline daily average. In order to maintain constant conditions and to maximize the flow rate of each filter over the time in which the experiment was conducted, constant head apparatuses similar to the one described by Salvinelli and Elmore [6] were used, as shown in Fig. 1. Likewise, the pump timer frequency was installed and the water was recirculated every 15 min. The float valve was adjusted to maintain a constant water level $40 \mathrm{~cm}$ above the sand.

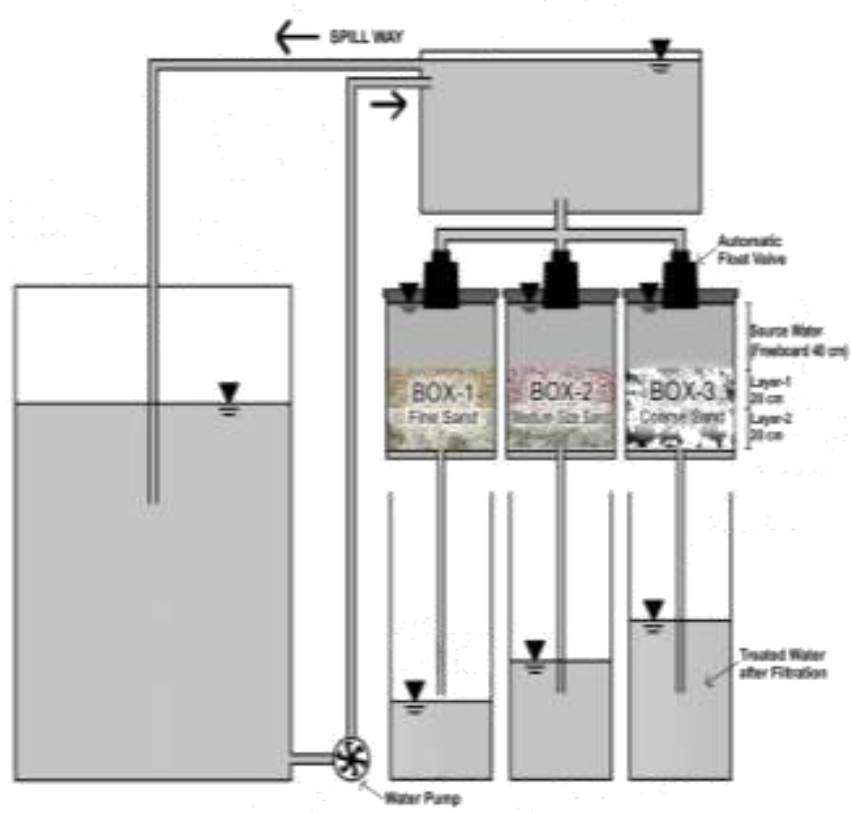

Fig. 1. Three parallel sand boxes with constant head apparatus (after Salvinelli et al. [7]).

Experiments were conducted over a 30-day period. The daily average flow rate $(\mathrm{Q})$ was measured by dividing the volume of treated water by the number of hours that had passed since the previous measurement and recorded as litres per hour. The turbidity (T) of the influent and effluent water was also measured every day for each filter using a turbidimeter with a detection limit of 0.01 NTU. Influent water samples were taken from the float valves' outflow and immediately analysed in duplicate. Effluent water samples were taken from the treated water container. On days 10 and 20 , the systems were stopped and, once empty, the filters were rinsed to remove particles rejected by the filtering unit. Then, a sample of influent water was taken from ports installed between the tank and automatic float valve, and the treated water collected in the bucket was analysed for turbidity.

The collected data were then analysed in order to evaluate any relationship between the measured parameters and to assess any impact on the sand filtration's flow rate and turbidity after filtration. The statistical software MS Excel 2010 was used to perform the data analysis.

\section{RESULTS AND DISCUSSION}

The daily average flow rate in each system versus the cumulative volume of treated water is presented in Fig. 2. Boxes 1, 2, and 3 followed the typical pattern with an initial increase until the maximum flow rate was reached and a subsequent decrease with an almost linear trend. The initial increase in flow rate seems to be caused by the material washed out from the sand filter during the first phase of the exercise, and was documented by Lantagne et al. [4], Hubbel et al. [2], Salvinelli and Elmore [6], and others. 


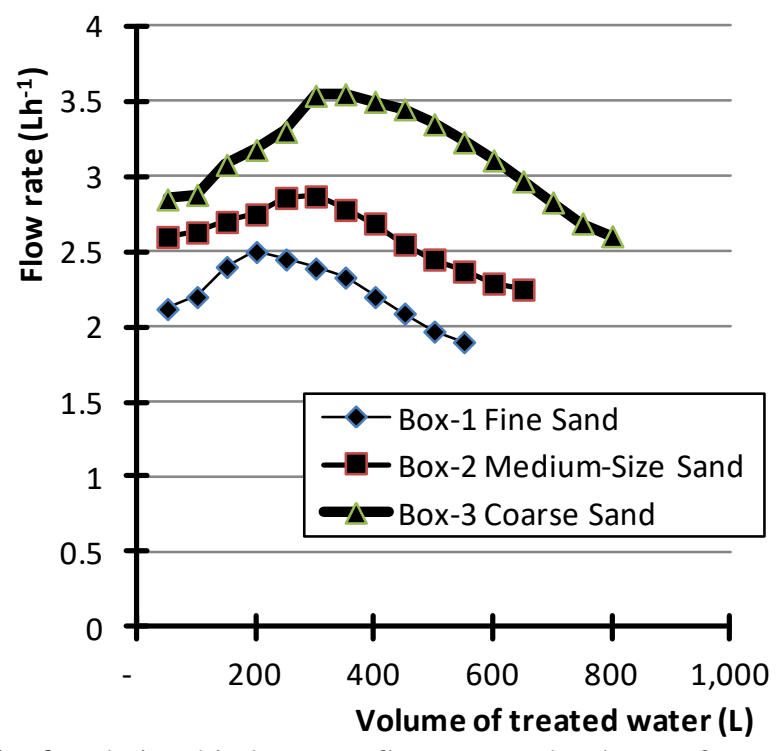

Fig. 2 Relationship between flow rate and volume of treated water in the first 10 days

The graph indicates how a smaller size of sand corresponds to lower average and maximum flow rates of water production capacity. After the filtration process had run for 10 days, the sand filters were rinsed to remove particles rejected by the filtering unit. This process was repeated over the next 10 days until the duration of the experiment reached
30 days. Table 1 shows the total volume of treated water for the first 10 days, the second, and the third.

Table 1 The total volume of treated water

\begin{tabular}{|l|l|l|l|}
\hline & \multicolumn{3}{|l|}{$\begin{array}{l}\text { The total volume of treated } \\
\text { water (L) }\end{array}$} \\
\cline { 2 - 4 } & $\begin{array}{l}\text { First 10 } \\
\text { days }\end{array}$ & $\begin{array}{l}\text { Second } \\
\text { 10 days }\end{array}$ & $\begin{array}{l}\text { Third 10 } \\
\text { days }\end{array}$ \\
\hline Box 1 (fine sand) & 535.6 & 530.4 & 513.6 \\
\hline $\begin{array}{l}\text { Box 2 (medium-size } \\
\text { sand) }\end{array}$ & 623.8 & 614.4 & 580.8 \\
\hline Box 3 (coarse sand) & 751.7 & 739.2 & 724.8 \\
\hline
\end{tabular}

The volume of treated water in the same box decreased along the duration of the experiment. No evidence of flow rate recovery was detected after the sand filters were rinsed on days 10 and 20. The statistical information that describes the average flow rate for the entire duration of the experiment (Qa) for each box is summarized in Table 2. The parameters were also tested for normality. The probability plot showed that normal distributions fitted, with all data points falling in the $95 \%$ confidence intervals for each parameter. Therefore, Qa data are from a normally distributed population.

Table 2 Statistical summary of flow rate data

\begin{tabular}{|c|c|c|c|c|c|c|c|c|c|}
\hline \multirow{3}{*}{ Variables } & \multicolumn{9}{|l|}{$\mathrm{Qa}\left(\mathrm{Lh}^{-1}\right)$} \\
\hline & \multicolumn{3}{|c|}{ Box 1 (Fine Sand) } & \multicolumn{3}{|c|}{ Box 2 (Medium-Size Sand) } & \multicolumn{3}{|c|}{ Box 3 (Coarse Sand) } \\
\hline & $\begin{array}{l}\text { First } 10 \\
\text { days }\end{array}$ & $\begin{array}{l}\text { Second } 10 \\
\text { days }\end{array}$ & $\begin{array}{l}\text { Third } \\
10 \text { days }\end{array}$ & $\begin{array}{l}\text { First } 10 \\
\text { days }\end{array}$ & $\begin{array}{l}\text { Second } 10 \\
\text { days }\end{array}$ & 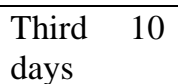 & $\begin{array}{l}\text { First } 10 \\
\text { days }\end{array}$ & $\begin{array}{l}\text { Second } 10 \\
\text { days }\end{array}$ & $\begin{array}{l}\text { Third } \\
10 \text { days }\end{array}$ \\
\hline $\mathrm{N}$ & 10 & 10 & 10 & 10 & 10 & 10 & 10 & 10 & 10 \\
\hline Mean & 2.23 & 2.21 & 2.14 & 2.60 & 2.56 & 2.42 & 3.13 & 3.08 & 3.02 \\
\hline Std dev. & 0.198 & 0.192 & 0.185 & 0.206 & 0.202 & 0.198 & 0.306 & 0.302 & 0.296 \\
\hline Minimum & 1.9 & 1.87 & 1.85 & 2.25 & 2.21 & 2.20 & 2.60 & 2.58 & 2.51 \\
\hline Maximum & 2.5 & 2.45 & 2.44 & 2.87 & 2.84 & 2.74 & 3.55 & 3.51 & 3.44 \\
\hline
\end{tabular}

Based on Table 2, the larger sand size gives a higher flow rate. The highest average flow rate is $3.13 \mathrm{Lh}^{-1}$ and occurs in Box 3. Figure 3 shows the positive linear relationship with $\mathrm{R}^{2}=0.988$.

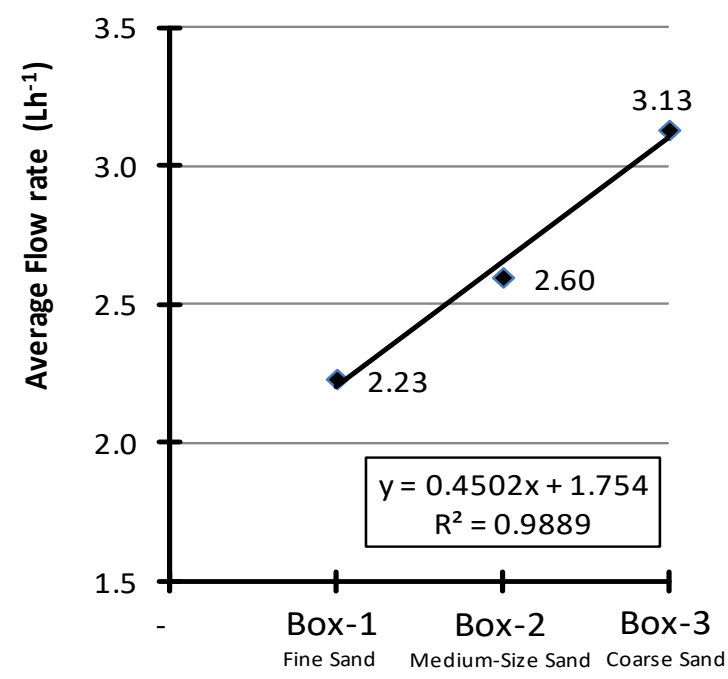

Fig. 3 Relationship between average flow rate and sand size 
The turbidity of the source water before filtration for all systems collected during the whole period of the experiment ranged from 9 to 8 NTU. After the filtration process, the turbidity decreased, as summarized in Fig. 4. The plot shows that the variability of turbidity increases when the sand is larger. The turbidity values range up to 6 NTU in the case of source waters treated by sand filtration in Box 3 . Figure 4 describes the positive linear relationship with $\mathrm{R}^{2}=0.975$.

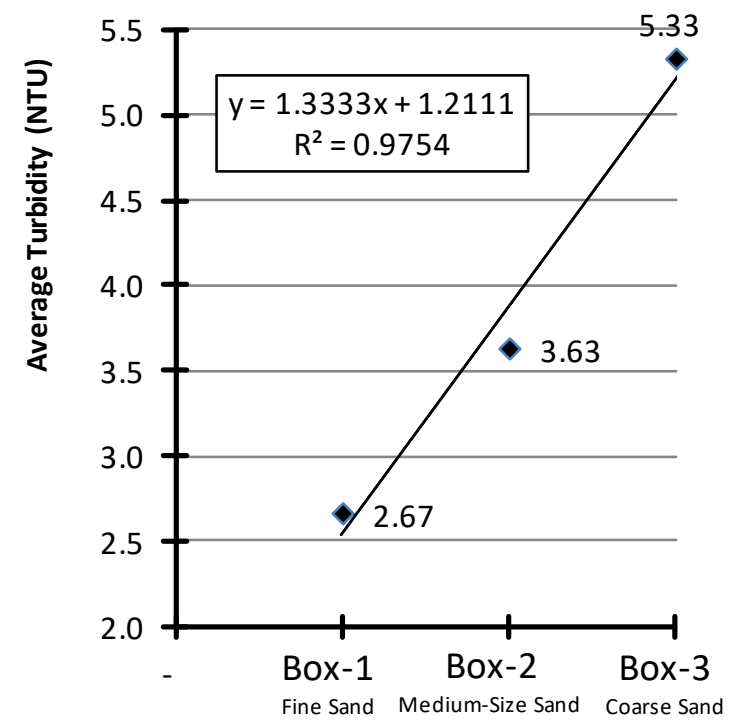

Fig. 4 Relationship between average turbidity rate and sand size

The degree of linear relationship between flow rate and effluent turbidity was measured. This is elaborated in Fig. 5.

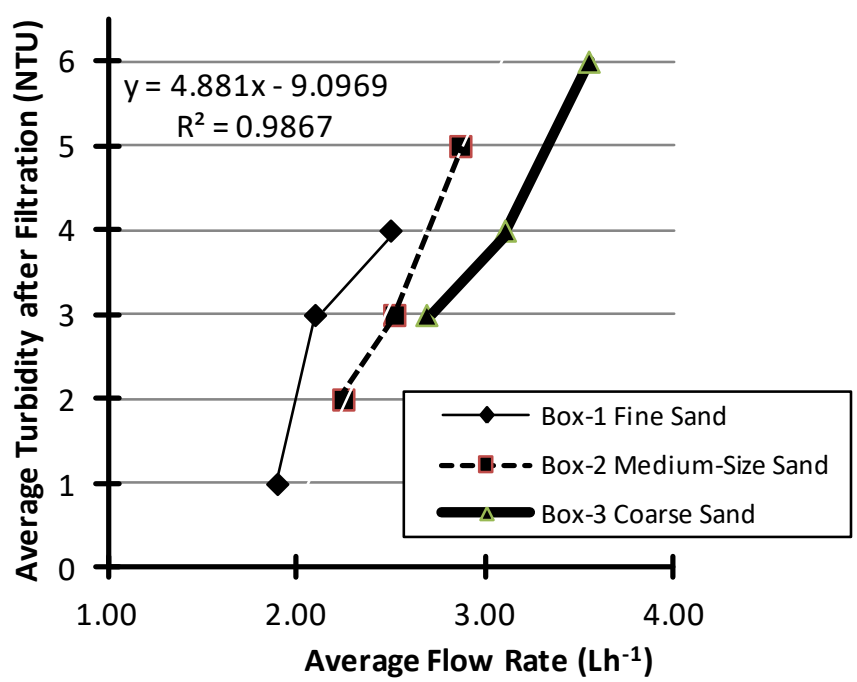

Fig. 5 Relationship between average flow rate and average turbidity after filtration

In order to characterize the impact of turbidity in the water source on the filter production capacity, the average flow rates of the three boxes associated with the systems were plotted against the average turbidity for each scenario, as shown in Fig. 5. The graph shows that a higher flow rate of water production will cause higher turbidity levels. These data fitted a line with a rate of increase of $4.881 \mathrm{NTU} / \mathrm{Lh}^{-1}$ and an R-squared value of 0.986. In addition, the Pearson product moment correlation coefficient was calculated with a result of 0.991 . The null hypothesis that the correlation equals zero was rejected with a p-value of 0.007 .

The initial turbidity before filtration is about 9 to 8 NTU, and after filtration the turbidity decreases, reaching only 6 NTU for Box 3. However, the Decree of the Indonesian Health Minister No. 907/MENKES/SK/VII/2002 [3] specifies that the maximum turbidity for clean water is 5 NTU. Therefore, based on Fig. 4, Box 3 is not able to reduce turbidity to the maximum level of 5 NTU given by the standard; on the other hand, Boxes 1 and 2 fulfil the standard. This finding is also highlighted by Fig. 5, which shows that Box 3 produces turbidity of up to 6 NTU, which does not correspond with the Indonesian standard. Therefore, the effective sand size for a reliable water filter is that use in Box 2, with a flow rate of up to $2.9 \mathrm{Lh}^{-1}$.

\section{CONCLUSION}

It is concluded that a relationship between the average flow rate of sand filtration and turbidity exists. A higher flow rate will produce a higher turbidity level. This relationship has a positive linear trend with a rate of increase of 4.881 $\mathrm{NTU} / \mathrm{Lh}^{-1}$. As the flow rate is the important factor for achieving slow filtration in terms of making an effective choice, Box 2 is the best solution to this matter. People in the surroundings of Mount Merapi can make use of this finding by developing sand filters like Box 2 for daily life, as long as regular rinsing is carried out every 10 days.

However, given the relatively short period (30 days) over which these experiments were conducted, results from longterm investigations such as those presented in Salvinelli and Elmore [6] should be taken into consideration before attempting to use the relationships developed in this paper to estimate flow rates over the potential lifetime of a sand filter.

\section{ACKNOWLEDGMENT}

Some works contributing to this paper were funded by Research Grant 2016 from the Ministry of Technology, Research, and Higher Education. The authors are grateful to the management of the Faculty of Civil Engineering and Planning, Universitas Islam Indonesia (UII), which provided the research infrastructure for this research. In particular, the authors would like to thank Dr Widodo Brontowiyono for granting access to the Innovation Center at UII.

\section{REFERENCES}

[1] Bendida, A., Tidjani, A.E.B., Badri, A., Kendouci, M.A., Nabou, M., 2013. Treatment of domestic wastewater from the town of Bechar by a sand filter (sand of Beni Abbes Bechar Algeria). Energy Procedia 36 (2013) 825-833.

[2] Hubbel, L., Elmore, A.C., Reidmeyer, M., 2015. Comparison of a native clay soil and an engineered clay used in experimental ceramic pot filter fabrication. Water Sci. Technol. Water Supply 15 (3), 569-577. 
[3] Indonesian Health Minister, Decree No. 907/MENKES/SK/VII/2002: Standard for Clean Water

[4] Lantagne, D., Klarman, M., Mayer, A., Preston, K., Napotnik, J., Jellison, K., 2010. Effect of production variables on microbiological removal in locallyproduced ceramic filters for household water treatment. Int. J. Environ. Health Res. 20 (3), 171-187.

[5] Mihelcic, J.R., Fry, L.M., Myre, E.A., Phillips, L.D., Barkdoll, B.D., 2009. Field Guide to Environmental Engineering for Development Workers. American Society of Civil Engineers, Reston, VA, USA, p. 550.

[6] Salvinelli, C., Elmore, A.C., 2015. Assessment of the impact of water parameters on the flow rate of ceramic pot filters in a long-term experiment. Water Sci. Technol. Water Supply 15 (6), 1425-1432.

[7] Salvinelli, C., Elmore, A.C., Reidmeyer, M.R., Drake, K.D., Ahmad, K.I., 2016. Characterization of the relationship between ceramic pot filter water production and turbidity in source water. Water Res. 104 (2016) 28-33.

[8] Utomo, S., Sir, T.M.W., Sonbay, A., 2012. Desain saringan pasir lambat pada instalasi pengolahan air bersih (IPAB) Kolhua Kota Kupang. Jurnal Teknik Sipil 1(4) (Sept.), 38-46.

[9] Van Halem, D., Van der Laan, H., Heijman, S.G.J., van Dijk, J.C., Amy, G.L., 2009. Assessing the sustainability of the silver-impregnated ceramic pot filter for low-cost household drinking water treatment. Phys. Chem. Earth 34 (1e2), 36-42. 